\title{
The nurturing of nature
}

\section{Review of Blueprint: how DNA makes us who we are, Robert Plomin, MIT Press, 2018, ISBN: 9780262039161, Hardcover: \$27.95 / €19.32 (starting from)}

\author{
Barbara A. Jennings ${ }^{1}{ }^{1}$ \\ Received: 4 June 2019 / Accepted: 5 June 2019 / Published online: 21 June 2019 \\ (c) European Society of Human Genetics 2019
}

I had expected this study of psychology and genetics to remind me of Philip Larkin's immortal words about how our parents mess us up, albeit without meaning to [1].

In Blueprint, however, Plomin [2] explains that the most significant, systematic influence that parents have on their children's psychological traits is via their DNA sequence. He supports this assertion with evidence from studies conducted over many decades. Blueprint has been criticised for being a manifesto for genetic determinism, but in my opinion that is a misreading of the book. Plomin is clear that for each complex trait studied, genetic factors can only explain about half of the variance observed. There is no doubt that environmental factors and chance are very important, but how these factors will play out is unpredictable.

Twin and adoption studies reproducibly show that environmental influences on psychological variance come from random experiences, with temporary impacts, as well as from systematic family-based factors. Whereas, inherited genetic factors have a consistent and lifelong impact when considered in aggregate. Furthermore, Plomin explains that some of the environmental measurements that psychologists study within families have a genetic basis themselves.

Another unequivocal conclusion from the research described in Blueprint is that the genetic risk for psychological pathology is continuous, not dichotomous, which has implications for the classification and treatment of psychiatric disorders.

This book is an engaging read. It has been structured to meet the needs of both the novice, who wants an introduction to DNA variation, and the geneticist, who wants an

Barbara A. Jennings

B.Jennings@uea.ac.uk

1 Norwich Medical School, University of East Anglia, Norwich NR4 7TJ, UK overview of psychological traits and psychiatric conditions. To illustrate this, one chapter (DNA: the basics) is a succinct summary of the biology and DNA technology that every reader needs to grasp to follow Plomin's ideas. Some concepts, and a discussion of sources, are confined to very detailed and interesting notes at the back of the book, which can be dipped into as needed.

The chapters in Part One of Blueprint focus on $>40$ years of twin and adoption studies-which uncovered the significance of genetics to the variation studied. Part Two of the book (The DNA Revolution) highlights association studies, and how international research consortia and big data have revealed some of the genetic architecture of psychological and psychiatric traits. Along the way, Plomin unpicks tricky concepts such as heritability, genetic amplification, regression to the mean, and how polygenic risk scores (PRS) can be used as predictive markers. He explains the design of genome-wide association studies; and how revolutionary they were for revealing the variants that contribute to complex phenotypes. That is, when designed with sufficient power to identify variants with infinitesimally small effect sizes.

One reason the book is so interesting is that Plomin reveals far more of himself than most scientists risk. He shares the highs and lows of his career; his ethos and hopes for a just society that embraces and respects genetic diversity; he even shares his PRS data (see chapter 13). His reflections on his own PRS opens up discussions of the ethical aspects of genetic science, and the dilemmas associated with data from probabilistic tests. This is a particular challenge for incurable conditions, such as late onset Alzheimer's disease, where a particular variant of the APOE gene does most of the "heavy lifting" for the PRS. Robert Plomin advocates the potential of PRS to contribute positively to personalised medicine and to the early identification and nurture of our authentic selves (nature). For balance, I think there should have been more critical appraisal of the clinical validity and utility of PRS for 
complex traits, because this is a controversial topic. In particular, while these probabilistic scores can predict average phenotypes for populations very well, there is a wide range of individual difference within each overlapping group. In addition, there is still a good deal of heritability that remains unexplained, for the phenotypes discussed.

However, some of the potential problems of using PRS are faced squarely, and chapter 9 (Equal opportunity and meritocracy) is an interesting examination of social and genetic science, and in particular how genetics might be used to affect upward and downward social mobility. Plomin challenges the value systems that could result in genetic discrimination, and explores the principles of a just society. I appreciate Plomin's thesis here because I have always wondered why the term meritocracy is used so positively and without challenge in academic and political circles. After all, it was coined with sarcasm in the 1950s and used in a dystopian novel, where one hierarchy (based on class) was replaced with another undesirable hierarchy based on educational elitism [3].

I think Robert Plomin's take on our genetic legacy, and how our knowledge of it could be applied, is less fatalistic and much more optimistic than Larkin's famous reflections on nurture. As for the social and clinical utility of PRS for most individuals? This story will unfold, and I still need to be convinced.

\section{Compliance with ethical standards}

Conflict of interest Robert Plomin has allowed me to make reference to his PRS data in a piece of my own writing for the manuscript of a genetics textbook.

Publisher's note: Springer Nature remains neutral with regard to jurisdictional claims in published maps and institutional affiliations.

\section{References}

1. Larkin P. This Be The Verse from High Windows (Faber, London, 1974).

2. Plomin R. Blueprint: how DNA makes us who we are (MIT Press Cambridge, Massachusetts, 2018).

3. Zimmer B. A 'Meritocracy' is not what people think it is, https://www.theatlantic.com/entertainment/archive/2019/03/ college-admissions-scandal-what-meritocracy-really/584875/ (accessed 25 May 2019). 